\title{
It could work!
}

\author{
Michele Di Mauro, MD, PhD, Fabrizio Tancredi, MD, Gerardo Liberti, MD, and Massimiliano Foschi, MD
}

\author{
From the Department of Cardiac Surgery, SS Annunziata Hospital, Chieti, Italy. \\ Disclosures: Authors have nothing to disclose with regard to commercial support. \\ Received for publication May 3, 2017; accepted for publication May 11, 2017; available ahead of print June 28, \\ 2017. \\ Address for reprints: Michele Di Mauro, MD, PhD, Department of Cardiac Surgery, SS Annunziata Hospital, Via \\ dei Vestini, Chieti 66100, Italy (E-mail: mdimauro1973@gmail.com). \\ J Thorac Cardiovasc Surg 2017;154:875-6 \\ $0022-5223 / \$ 36.00$ \\ Copyright (c) 2017 by The American Association for Thoracic Surgery \\ http://dx.doi.org/10.1016/j.jtcvs.2017.05.039
}

When I read the article by Weiser and coworkers, ${ }^{1} 2$ scenes of the famous movie Young Frankenstein ${ }^{2}$ came to mind: In the first scene, a skeptical Gene Wilder stated "You have more chance of reanimating this scalpel than you have to mending a broken nervous system." In the second scene, he shouted the famous sentence "It could work!" realizing he was able to give new life to Frankenstein. This animal study was well performed and proved to be a smart idea to improve the chances for emergency preservation and resuscitation in case of cardiac arrest (CA).

CA is a major cause of mortality and neurologic disability. The incidence of out-of-hospital $\mathrm{CA}$ is approximately 80 patients per 100,000 persons annually. Despite advances in resuscitation, outcomes remain dismal, with $10 \%$ of patients surviving until hospital discharge and $5 \%$ experiencing full neurologic recovery. ${ }^{3}$

The primary determinant of outcome after CA is hypoxic ischemic brain injury. Hypoxic ischemic brain injury is the primary cause of death in $68 \%$ of inpatient CA and in $23 \%$ of out-of-hospital CA. ${ }^{4}$

Brain injury after CA is the main cause of mortality and long-term neurologic disability in survivors. Injures after CA can be classified as primary and secondary. ${ }^{5}$

The primary brain injury after $\mathrm{CA}$ is due to sudden cessation of oxygen delivery, resulting in neuronal ischemia and cell death by few minutes. Oxygen-delivery cessation causes energy-dependent ion channel function with subsequent edema, anaerobic metabolism, cerebral lactate, and activation of lytic enzymes up to apoptosis. ${ }^{5}$

Hypothermia historically has been the main tool to address both primary and secondary cerebral injuries after CA. ${ }^{6}$ Cerebral metabolism is reduced by $5 \%$ to $10 \%$ per $1^{\circ} \mathrm{C}$ decrease in core body temperature. In addition, global carbon dioxide production and oxygen consumption are decreased proportionally to reductions in core body temperature. 7 By decreasing cerebral metabolism, hypothermia avoids excessive intracellular anaerobic metabolism, improves cerebral glucose use, allows available cellular energy stores, prevents apoptosis, and reduces inflammatory response. Thus, since 1950, hypothermia has

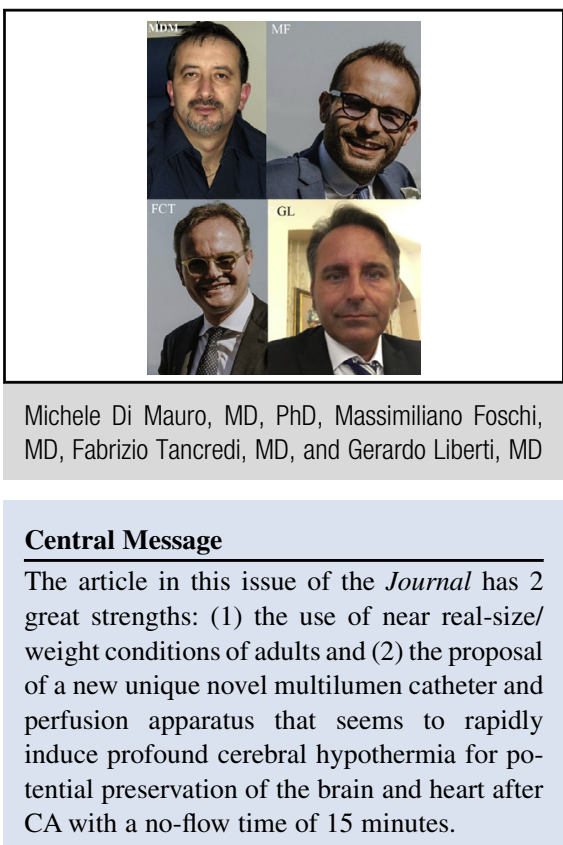

See Article page 867 .

been considered one of the best protectors of the neurologic system, especially for the brain, in congenital and aortic arch surgery.

Although many studies have focused on the binomial hypothermia and emergency preservation and resuscitation, there are 2 important insights of the present animal study: the use of near real-size/weight conditions of adults and the proposal of a new unique novel multilumen catheter and perfusion apparatus that seems to rapidly induce profound cerebral hypothermia for potential preservation of the brain and heart after $\mathrm{CA}$ with a no-flow time of 15 minutes.

The median cooling rate was $1.3^{\circ} \mathrm{C} / \mathrm{min}$, reaching the target of $5 \%$ to $10 \%$ of cerebral metabolism reduction per minute. Because of the flush solution, a lot of blood pooled into the peripheral veins and arteries, which along with venting allows maintenance of a good level of hemoglobin. It is well known that hemoglobin is a major determinant of arterial oxygen content because it is involved in the secondary injury.

Another strength of the present study is that Weiser and coworkers ${ }^{1}$ clearly identified the necessity for the precise catheter placement below the separation of the truncus brachiocephalicus in the aorta, a key point for effective cooling of the brain. This has never been reported before and seems to be critical for effectively cooling the brain. 
Although Weiser and coworkers ${ }^{1}$ concluded that future refinements in flush catheter design are needed to simplify the procedure and to develop the optimal "flush cocktail" to improve the effectiveness, let's say "It could work!"

\section{References}

1. Weiser C, Weihs W, Holzer M, Testori C, Kramer A-M, Kment C, et al. Feasibility of profound hypothermia as part of extracorporeal life support in a pig model. $J$ Thorac Cardiovasc Surg. 2017;154:867-74.

2. http://www.imdb.com/title/tt0072431/quotes.
3. Gräsner JT, Lefering R, Koster RW, Masterson S, Böttiger BW, Herlitz J, et al. EuReCa ONE—-27 Nations, ONE Europe, ONE Registry: a prospective one month analysis of out-of-hospital cardiac arrest outcomes in 27 countries in Europe. Resuscitation. 2016;105:188-95

4. Laver S, Farrow C, Turner D, Nolan J. Mode of death after admission to an intensive care unit following cardiac arrest. Intensive Care Med. 2004;30:2126-8.

5. Sekhon MS, Ainslie PN, Griesdale DE. Clinical pathophysiology of hypoxic ischemic brain injury after cardiac arrest: a "two-hit" model. Crit Care. 2017;21:90.

6. Polderman KH. Induced hypothermia and fever control for prevention and treatment of neurological injuries. Lancet. 2008;371:1955-69.

7. Polderman KH. Mechanisms of action, physiological effects, and complications of hypothermia. Crit Care Med. 2009;37(7 Suppl):S186-202. 